\title{
SEROPREVALENCE OF BLOOD-BORNE INFECTIONS AND POPULATION SIZES ESTIMATES IN A POPULATION OF INJECTING DRUG USERS IN CROATIA
}

\author{
Branko Kolarić ${ }^{1}$, Dinko Štajduhar ${ }^{2}$, Davorin Gajnik ${ }^{1}$, Tomislav Rukavina ${ }^{3}$, Lucas Wiessing ${ }^{4}$ \\ IPublic Health, Social Medicine and Gerontology Service, Zagreb County Institute of Public Health, Zagreb, Croatia \\ ${ }^{2}$ Neuropsychiatric Hospital "Dr. Ivan Brbot", Popovača, Croatia \\ ${ }^{3} S$ chool of Medicine, University of Rijeka, Rijeka, Croatia \\ ${ }^{4}$ European Monitoring Center for Drugs and Drug Addiction, Lisbon, Portugal
}

\begin{abstract}
SUMMARY
Similar to some other Central European countries, Croatia has low HIV prevalence among injecting drug users (IDUs) but high hepatitis C (HCV) prevalence. This may indicate different patterns of risk behaviour in this region than in other parts of Europe. The main objectives of this study were to assess the seroprevalence of HIV and hepatitis B and C and related risk factors among IDUs in the three largest Croatian cities (Zagreb, Split, Rijeka) and within the national prison system, as well as to apply a multiplier-method population size estimation of IDUs in Zagreb, Split and Rijeka.

Recruitment sites were selected in collaboration with the local public health institutes, NGOs, Centers for treatment municipalities and the judiciary system. Participants were recruited during September and October 2007. Trained peer-recruiters were used to recruit IDU participants at treatment and harm reduction centres as well as pre-identified social, commercial and street based venues. Participants completed the study questionnaire and provided venous blood samples for HIV, hepatitis B and hepatitis C testing.

The study included 601 participants, of whom 121 were recruited in Split, 130 in Zagreb, 150 in Rijeka and 200 in the prison system. The prevalence of positive anti-HCV tests was $65 \%$ in Split, $51 \%$ in Zagreb, $29 \%$ in Rijeka and $44 \%$ in the prisons. The prevalence of anti-HBcAg was $31 \%$ in Split, 13\% in Zagreb, $9 \%$ in Rijeka and 24\% in prison. No case of HIV infection was found. The estimated IDUs population sizes were 2,805 for Zagreb area, 3,347 for $S$ plit and 1,370 for Rijeka area, however confidence intervals were very large, indicating the need for larger samples.

A high frequency of positive markers on hepatitis $B$ virus and $C$ virus in the population of injecting drug users in Croatia has been confirmed with this research, as well as a low prevalence of HIV infection. This may be related to relatively low levels of injecting risk behaviour and injecting frequency although it is not possible to make strong conclusions on risk behaviour, as participants were mostly recruited in harm reduction programmes. This research should be followed by targeted activities for reducing risks of infectious diseases among injecting drug users in the Republic of Croatia and future research at the national level.
\end{abstract}

Key words: injecting drug use, Croatia, size estimate, HIV, hepatitis, prevalence

Address for correspondence: B. Kolarić, Zavod za javno zdravstvo Zagrebačke županije, Matice hrvatske bb, 10410 Velika Gorica, Croatia. E-mail: branko.kolaric@gmail.com

\section{INTRODUCTION}

Injecting drugs by using non-sterile equipment is a known direct risk for blood-borne infectious diseases. According to the estimates of UNAIDS and the World Health Organization (WHO), $0.6 \%$ of world population (33 million) is infected with HIV, $3 \%$ (170 million) with hepatitis C (HCV) and 7\% (400 million) with hepatitis B (HBV) (1, 2). These infections are transmitted by unprotected sexual contact with an infected person and contact of damaged skin or mucous membranes with infected blood.

Representative data on the spread of blood borne diseases among the injecting drug users (IDU) population are difficult to obtain. Since drug use is an illegal activity. IDUs may decide not to participate in surveys due to the fear for legal consequences.
According to available estimates, there are some $0.8-1.3$ million IDUs in Western Europe, of which roughly about 100,000 $(39,000-210,500)$ may be HIV infected (3-5). Globally, some 3 out of 16 million IDUs are estimated to be living with HIV, representing nearly $10 \%$ of all HIV/AIDS infected persons in the world (3). In the Republic of Croatia, reliable estimates of the IDU population size are not available, whilst in routine laboratory data the percentage of HIV positives among tested IDUs is approximately $0.6 \%$ (3). Similar to some other Central European countries, Croatia has a low HIV prevalence among drug users but high HCV prevalence (6-8) which may indicate different risk behaviour patterns as compared to other European countries. Taking into account sexual risk behaviours and the geographical proximity of countries with a high prevalence of drug use and HIV 
infected IDUs, several preconditions appear to exist for spread of HIV, HCV and HBV infections among IDUs in Croatia (9). Therefore, it is essential to conduct sero-behavioural surveys ('second generation HIV surveillance') that can help to validate the routine data and identify ways and patterns of risk exposure.

The main objectives of this study were to assess the seroprevalence of HIV, hepatitis B and C and related risk factors among IDUs in the three largest Croatian cities (Zagreb, Split, Rijeka) and within the national prison system, as well as to estimate the population size of IDUs in Zagreb, Split and Rijeka.

\section{MATERIALS AND METHODS}

\section{Sites and Participants Selection}

Due to the anticipated low prevalence of injecting drug use in rural areas, only urban sites were selected (4). Three survey locations in Croatia were targeted (Zagreb, Rijeka and Split) along with prison settings. One prison (Remetinec in Zagreb) was selected due to a presumed high concentration of persons with high-risk behaviour that probably would not have been reached in the community. Prisoners were excluded from the IDU population size estimates because they did not represent any geographical area of Croatia and their results are shown separately - there is no overlap between the IDUs in prison and the IDUs participating in the three cities.

Within the survey locations, study recruitment sites were selected in collaboration with the local public health institutes, NGOs, Centers for treatment municipalities and the judiciary system. Priority was given to the three biggest NGOs (LET in Zagreb, HELP in Split and Terra in Rijeka) which are in contact regularly with a large number of IDUs.

The target population comprised injecting drug users attending selected harm reduction programs in communities and IDUs in prison settings. The sampling period was two months (September-October 2007).

The inclusion criteria for individuals who participated in the survey were as follows:

1. Belonging to target group IDUs (having injected at least once in the last 12 months).

2. Informed consent must have been obtained to participate in the survey.

3. Respondents having had taken part in previous survey were not sampled in the current one.

4. Underage respondent $(<18)$ had to have consent of their legal guardian.

\section{Community Based Recruitment}

Trained peer-recruiters were used to visit treatment and harm reduction centres as well as pre-identified social, commercial and street based venues in order to recruit IDU participants. In the previously mentioned centres, the participants completed the study questionnaire and at the same visit provided blood samples for HIV, hepatitis B and hepatitis C testing. Information about the study was provided to all potential participants by on-site counsellors. Respondents were informed that they would be able to obtain results of the tests and for those with positive results appropriate treatment would be provided. All participants received pre- and post-test counselling. In case of positive confirmatory test they were referred to treatment centres for infectious diseases. The informed consent was confirmed on the front page of the study questionnaire by the signature of the counsellor at the setting where the samples were collected. After filling out the questionnaire, patients received pre-test counselling focused on the interpretation of tests results and reducing future risk behaviours. The counselling was provided by the health care worker before the informed consent was signed and the blood samples were taken. The samples were labelled with a unique code and sent to the collaborating laboratory for testing. The same code was used to label the questionnaire and to link the results of the test with the participants (linked-anonymous proceedure). Questionnaires were collected and stored in a secure place for transport by the study coordinators. The results were given with the post-test counselling and, if needed, with referral to treatment and further care. Every participant received 7 Euros mobile phone subscription as an incentive for participation. Overall the procedures were in line with national recommendations as specified by Ministry of health and social welfare.

\section{Prison Settings Recruitment}

All imprisoned IDUs who met the inclusion criteria during the survey period were invited to participate in the survey. They received preventive educational material informing them on the risks of infections and protective measures. The procedures of counselling, collecting data and blood samples were the same as for the community based recruitment, except that prisoners did not receive incentives.

\section{Questionnaire}

An anonymous self-administered questionnaire (linked to the blood samples using a unique ID) was used to obtain quantitative and qualitative data related to the respondent's socio-demographic characteristics, HIV and viral hepatitises testing history, sexual health and sexual behaviour, and service access. The questionnaire was developed from the Family Health International (FHI) questionnaire for STI/HIV/AIDS Behavioural Surveillance and the EMCDDA protocol and example questionnaire for monitoring Drug Related Infectious Diseases (10). The questionnaire had 54 questions and in this paper we present only the main quantitative results. Representatives from relevant civil society organisations and relevant health care professionals, such as state epidemiologists, were asked to participate in the review of the questionnaires and ensure their appropriateness and acceptability among the target population.

\section{Testing of Blood Samples}

Ten millilitres of venous blood were drawn in a vacutainer tube, labelled and centrifuged. Samples were tested for HIV (anti HIV), hepatitis B (HBsAg, anti HBcAg, anti HBsAg) and hepatitis C (anti HCV) in the clinical hospital "Dr.Fran Mihaljevic" in Zagreb. The testing algorithm was in line with WHO recommendations and WHO evaluated methods. All samples underwent diagnostic testing which included: ELISA third generation tests for screening on HBV and HCV and ELFA fourth generation (11) for screening on HIV $1 / 2$. Since according to the manufacturer the mentioned tests have very high sensitivity (>99.99\%) there was likely almost zero probability of false negative results. All 
positive results on screening tests underwent confirmatory testing (RIBA, PCR, Western blott) $(12,13)$ with specificity $>99.99 \%$ to avoid false positive results.

\section{Statistical Analysis}

Differences between the study locations were evaluated using the $\chi^{2}$ test for categorical variables and the Kruskal-Walis test for numeric variables. Numeric variables were tested for normality distribution using the Kolmogorov-Smirnov test. SPSS software version 16.01 was used to perform the statistical analyses.

\section{Population Size Estimation}

The multiplier method was used for the population size estimation $(14,15)$, where benchmark values represented the number of registered treated injecting drug users in the Croatian National Registry of Treated Psychoactive Drug Addicts in 2006, and the multipliers were calculated based on the ratio of the median number of injecting drug users the participants reported being "friends" with and the median number of those "friends" they reported had been in treatment programmes in 2007. 95\%-confidence intervals were calculated using the normal approximation of the binomial distribution.

\section{Data Base and Ethical Approval}

The data base of this research is owned by the Ministry of Health and Social Welfare of the Republic of Croatia and the Office for Combating Psychoactive Drug Abuse of the Government of the Republic of Croatia, and it is available to be used for making secondary data analyses and the research results publications. The medical ethical committee's of the Ministry of Health and Social Welfare provided approval for conducting this research (March, 2007).

\section{RESULTS}

The study included a total of 601 participants. All participants accepted to fill out the questionnaire and give a blood sample. In Zagreb and Rijeka all the questionnaires were completed accurately. In Split, 22 out of 121 questionnaires were completed incorrectly due to the questionnaire not being correctly printed, i.e. three last pages were missing. Of these questionnaires we used the available 37 questions for the analysis and the remaining 17 questions were marked as "missing".

\section{Socio-demographic information}

Of the 601 participants, 121 were recruited in Split, 130 in Zagreb, 150 in Rijeka and 200 in prison. More than four fifths (83.3\%) of participants in the community samples were male, whereas in prison this was $93.3 \%$. Median, minimum and maximum ages are shown in Table 1.

According to educational level the locations were statistically significantly different $(\mathrm{p}<0.001)$. The largest proportion of nonskilled or low-skilled participants was found in Rijeka (30.7\%), and the largest number of participants with higher education in Zagreb (11\%). The highest unemployment rate was noticed among the participants in Split (72\%), followed by Zagreb (63\%) and Rijeka (55\%). The finding that $20 \%$ of participants in Zagreb, $16 \%$ in Split and 7\% in Rijeka had been homeless for more than
Table 1. Median and interquartile range for "age” variable according to research location

\begin{tabular}{|l|c|c|c|}
\hline & Age median & $\mathbf{2 5}$ percentile & $\mathbf{7 5}$ percentile \\
\hline Zagreb & 30 & 26 & 33 \\
\hline Rijeka & 26 & 24 & 30 \\
\hline Split & 29 & 26 & 35 \\
\hline Prison & 29 & 26 & 34 \\
\hline Total & 29 & 25 & 33 \\
\hline
\end{tabular}

a week during the last year points to their low socio-economic position. More than half of the participants in Zagreb (53\%), 42\% in Split and 33\% in Rijeka, who were reached through NGOs, had at a certain point of their life been imprisoned.

\section{Drug Use and Risk Behaviours for HIV, HBV and HCV Infection}

All participants were heroin injectors at the time of the study, and in all three cities these heroin injectors reported having started their drug use with marijuana (Rijeka $81 \%$, Split 76\%, Zagreb $65 \%$ ), whereas heroin was reported as the main drug of initiation by only $4 \%$ of participants in Split, $7.3 \%$ in Rijeka and $12.1 \%$ in Zagreb. The frequency of sharing drug injection equipment in the last year is shown in Table 2.

Table 2. Frequency of sharing of drug-injection equipment in the last 12 months according to location (\%)

\begin{tabular}{|l|c|c|c|c|}
\hline & Split & Zagreb & Rijeka & Total \\
\hline Always & 1.7 & 1.7 & 2 & 1.8 \\
\hline Most often & 1.7 & 1.7 & 2 & 1.8 \\
\hline About half times & 0 & 4.1 & 1.3 & 1.8 \\
\hline Sporadically & 26.9 & 20.7 & 23.5 & 23.7 \\
\hline Never & 69.7 & 52.1 & 69.1 & 64 \\
\hline Do not know & 0 & 15.7 & 2 & 5.7 \\
\hline $\begin{array}{l}\text { Do not want to } \\
\text { answer }\end{array}$ & 0 & 4.1 & 0 & 1.3 \\
\hline
\end{tabular}

From Table 3 it results that the examinees from Split have the longest record of drug injecting, the largest number of injections in the last month and the largest number of sexual partners in the last year, suggesting that the heroin epidemic in Croatia started in Split and then spread to Rijeka and Zagreb.

When it comes to high-risk sexual behaviour, i.e. non-usage of condoms during the last sexual intercourse, the results are as follows: in Split 55\% of the examinees did not use a condom during their last intercourse, whereas $72 \%$ examinees in Rijeka and $77 \%$ examinees in Zagreb did not use a condom during their last intercourse.

This research was the first occasion for $31.6 \%$ participants from Split, 22\% from Rijeka and 23.6\% from Zagreb to get tested on HIV, suggesting that testing coverage among IDUs in Croatia can be improved. 
Table 3. Answers to the questions with median presentation (interquartile range)

\begin{tabular}{|l|c|c|c|}
\hline & Split & Zagreb & Rijeka \\
\hline $\begin{array}{l}\text { Number of years since first drug } \\
\text { injection }\end{array}$ & $10(5-15)$ & $5(1-10)$ & $7(4-10)$ \\
\hline $\begin{array}{l}\text { Number of injections in the last } \\
\text { month }\end{array}$ & $10(2-40)$ & $0(0-5)$ & $0(0-4)$ \\
\hline $\begin{array}{l}\text { Number of persons the injection } \\
\text { equipment has been shared with } \\
\text { during the last month }\end{array}$ & $0(0-0)$ & $0(0-1)$ & $0(0-0)$ \\
\hline $\begin{array}{l}\text { Number of sexual partners in the } \\
\text { last year }\end{array}$ & $2(1-4)$ & $1(1-3)$ & $1(1-3)$ \\
\hline
\end{tabular}

\section{Seroprevalence of HIV, HBV and HCV}

Table 4 shows the results of testing the seroprevalence of markers of hepatitis B, antibodies to HCV and HIV. A relatively high frequency of positive on hepatitis $\mathrm{B}$ virus and $\mathrm{C}$ virus markers has been found, in combination with a low prevalence of HIV infection.

\section{Estimation of Population Sizes of Injecting Drug Users}

In Table 5 the results of population size estimation of injecting drug users in Zagreb, Split and Rijeka area are presented.

\section{DISCUSSION}

We found a high seroprevalence of anti-HCV and anti-HBV in our study population and no cases of HIV infection. The participants in Split have a statistically significant higher prevalence of antibodies to hepatitis C, while the participants in Split and those in prison had statistically significant higher prevalence of anti-HBcAg and anti-HBsAg as compared to Rijeka and Zagreb. The finding that none of the 601 participants had antibodies to HIV confirms the information from diagnostic testing data of the national laboratory based case reporting system, in which less than $1 \%$ of tests in IDUs are positive for HIV. These results are also in line with those from the neighbouring countries in the region (16, 17). There is still no reliable explanation for the differences among the epidemics of HIV among IDUs in some Eastern-European countries (Ukraine, Estonia, Russian Federation) in the last ten
Table 5. Estimation of the sizes of the injecting drug users' populations according to the location of research using the multiplier method

\begin{tabular}{|l|c|c|c|}
\hline & Benchmark & Multiplier & $\begin{array}{c}\text { Estimated population } \\
\text { size (range) }\end{array}$ \\
\hline $\begin{array}{l}\text { City of Zagreb and } \\
\text { the Zagreb County }\end{array}$ & 1,122 & $10 / 4$ & $2,805(1,515-9,313)$ \\
\hline $\begin{array}{l}\text { Split-Dalmatia } \\
\text { County }\end{array}$ & 502 & $20 / 3$ & $3,347(1,320-16,716)$ \\
\hline $\begin{array}{l}\text { Primorje-Gorski } \\
\text { kotar County }\end{array}$ & 411 & $20 / 6$ & $1,370(760-3,423)$ \\
\hline Croatia & 3,861 & $20 / 5$ & $15,444(7,876-42,896)$ \\
\hline
\end{tabular}

years and low prevalence of HIV in Southern-Eastern and Central Europe, as observed in this study. However our findings point to relatively low levels of injecting frequencies and injecting risk behaviour among IDUs comparing to some other eastern (18-20) as well as western European countries (21-24). These findings may partly explain the favourable epidemiological situation with regard to HIV in Croatia. However, they should be replicated in samples not restricted to IDUs attending drug services.

We found statistically significant differences in our data on knowledge, behaviour and seroprevalence among research sites, which may imply differences between IDU populations and a need for site-specific prevention activities. When looking at Table 3 and Table 4 (results section) in conjunction, it can be seen that the highest level of risk behaviour has been reported in Split, which is in line with the serological findings. It should however be taken into consideration that the results of the participants in Split are likely the least representative because the answer rate to these questions was the lowest in this area.

Quantitative studies of socio-demographic factors and behavioural factors indicate an association of the risk of blood borne diseases in IDU populations with unemployment, heroin as the starting drug of abuse, previous infection with viral hepatitis, alcohol abuse and not using condoms $(25,26)$, place of residence (27), malnutrition (28) and periods of stress, which may be associated with the initiation of drug use (29). A difference in risk of HIV infection in IDUs by gender has also been described. Risk factors for males are younger age and lack of family support, whilst risk factors for women are economic difficulties and having an IDU as sexual partner $(30,31)$.

Table 4. Results of serological tests according to research location

\begin{tabular}{|l|c|c|c|c|c|c|c|c|c|c|}
\hline \multirow{2}{*}{} & \multicolumn{2}{|c|}{ Split } & \multicolumn{2}{c|}{ Zagreb } & \multicolumn{2}{c|}{ Rijeka } & \multicolumn{3}{c|}{ Prison } & \multicolumn{2}{c|}{ Total } \\
\cline { 2 - 13 } & $\mathbf{p}^{+}$ & $\mathbf{C l}^{++}$ & $\mathbf{p}$ & $\mathbf{C l}$ & $\mathbf{p}$ & $\mathbf{C l}$ & $\mathbf{p}$ & $\mathbf{C l}$ & $\mathbf{p}$ & $\mathbf{C l}$ \\
\hline HBsAg & 1.7 & $0.2-6$ & 0.8 & $0-4.2$ & 0.7 & $0-3.7$ & 0.5 & $0-2.7$ & 0.8 & $0.3-1.9$ \\
\hline Anti HBCAg* & 31 & $23-40$ & 13 & $8-20$ & 9 & $5-15$ & 24 & $18-31$ & 20 & $16-23$ \\
\hline Anti HBsAg & 13 & $8-20$ & 8 & $4-14$ & 7 & $3-12$ & 15 & $4-12$ & 11 & $9-14$ \\
\hline Anti HCV & 65 & $56-73$ & 51 & $42-60$ & 29 & $22-36$ & 44 & $37-51$ & 46 & $41-50$ \\
\hline Anti HIV & 0 & $/$ & 0 & $/$ & 0 & $/$ & 0 & $/$ & 0 & $/$ \\
\hline
\end{tabular}

${ }^{*}$ statistically significant difference on $5 \%$ level

+ prevalence (\%)

$++95 \%$ confidence interval 
Harm reduction, together with HIV prevention includes the prevention of viral hepatitis B and C (32, 33), but unfortunately trends in HCV prevalence often do not follow declines in HIV prevalence in IDUs (34), likely due to the higher infectivity of HCV. Harm reduction also includes needle and syringe exchange programmes among a range of measures, which may be more effective if implemented in low-threshold civil society organizations (e.g. drop-in centres), as compared to general heath institutions or locations with regular presence of police (35-37). Besides needle and syringe programmes, opioid substitution and other drug treatment, ART, vaccination, diagnosis and treatment of viral hepatitis are among nine interventions in a comprehensive package of services for injecting drug users recommended by WHO, UNODC and UNAIDS (33). In addition to the blood-borne transmission through drug injecting, it is necessary to prevent sexual transmission of those viruses through the increase of condom use $(38,39)$. Moreover, it is important to ensure the availability of sufficient voluntary counselling and testing centres (VCT) to prevent persons from risk groups to voluntary donate blood for the sake of knowing their test result. It is further necessary to strengthen preventive activities among IDUs in order to avoid future increases in risk behaviour and an epidemiological situation similar to the one currently seen in the Eastern Europe (40).

This survey provides base-line information for future monitoring of blood borne diseases seroprevalence among IDUs and first estimates of IDU population size in Zagreb, Split and Rijeka. The results need to be further validated and monitored by repeated surveys (preferably generalizable to the national level) and using other methods for estimating the size of the problem of drug user population (41). The experience gained in our study is important for the further development of IDU specific surveillance in Croatia. The procedure of motivating the examinees by granting them a mobile phone subscription appeared to be very efficient as a high percentage of participants filled out the questionnaire composed of 54 questions.

Our study has several limitations. The selection of participants through addiction prevention centres might have led to a lower generalisability of results, since we did not manage to reach the parts of the IDU population not included in the treatment and harm reduction programmes. In the future other approaches that can reach IDUs not attending services, such as respondent driven sampling, may be considered. We have further possibly introduced selection bias by providing incentives as a motivation for entering the research - some IDUs with better socio-economic status may have been less motivated than ones with low incomes. The answer rate for some questions regarding how much the examinees know about risks was very low (38/121), particularly among the examinees from Split. Such a large non-response on some questions made those results less reliable and potentially distorted. Behavioural data from the prison system could not be used due to a systematic mistake and was excluded from analysis, from this setting only the biological results were used.

Regarding the laboratory testing procedure, however, we ensured diagnostic testing and, therefore, the maximum possible validity and accuracy of the seroprevalence data. Finally, our population size estimates should be regarded as first pilot estimations and in future studies larger datasets should be obtained in order to reduce the size of the confidence intervals.

\section{CONCLUSION}

With this research, on a sample of 601 IDUs, a relatively high frequency of positive markers on hepatitis B virus and $C$ virus has been found, in combination with a low prevalence of HIV infection in the population of injecting drug users in Croatia. This study should be followed by targeted activities for reducing risks of infectious diseases among injecting drug users in the Republic of Croatia and should stimulate future monitoring and research in IDUs.

\section{Acknowledgements}

The Office for Combating Psychoactive Drug Abuse of the Government of the Republic of Croatia and the Ministry of Health and Social Welfare of the Republic of Croatia ordered conducting the research, whereas the resources were assured by the European Monitoring Centre for Drugs and Drug Addiction, within the framework of the regional PHARE programme for the Republic of Croatia and Turkey. The authors would like to thank all research staff, especially the research team leaders: Zorana Klismanic, Dana Pahor, Mirjana-Lana Kosanovic and Vitomir Burek.

\section{REFERENCES}

1. HIV/AIDS data and statistics [Internet]. Geneva: World Health Organization [cited 2009 Aug]. Available from: http://www.who.int/hiv/data/en/

2. Report on the global HIV/AIDS epidemic 2008: executive summary [Internet]. Geneva: UNAIDS [cited 2009 Aug]. Available from: http:// data.unaids.org/pub/GlobalReport/2008/JC1511_GR08_ExecutiveSummary_en.pdf.

3. Mathers B, Degenhardt L, Phillips B, Wiessing L, Hickman M, Strathdee SA, et al; 2007 Reference Group to the UN on HIV and Injecting Drug Use. Global epidemiology of injecting drug use and HIV among people who inject drugs: a review. Lancet. 2008 Nov 15;372(9651):1733-45.

4. Wiessing L, Likatavičius G, Klempová D, Hedrich D, Nardone A, Griffiths P. Associations between availability and coverage of HIV-prevention measures and subsequent incidence of diagnosed HIV infection among injection drug users. Am J Public Health. 2009 Jun;99(6):1049-52.

5. European Monitoring Centre for Drugs and Drug Addiction. Annual Report 2007: the state of the drugs problem in the European Union [Internet]. Luxembourg: Office for Official Publications of the European Communities; 2007 [cited 2008 Sep 22]. Available from: http://www. emcdda.europa.eu/publications/annual-report/2007.

6. Gyarmathy VA, Neaigus A. Marginalized and socially integrated groups of IDUs in Hungary: potential bridges of HIV infection. J Urban Health. 2005 Sep;82(3 Suppl 4):101-12.

7. Croatian National Institute of Public Health. Report on treatment of drug users in Croatia in 2005. Zagreb: Croatian National Institute of Public Health; 2006. (In Croatian.)

8. Kolaric B, Pavlic J. HIV/AIDS surveillance in Croatia. Zagreb (CRO): Croatian National Institute of Public Health; 2007.

9. Family Health International [Internet]. Arlington: FHI [cited $2007 \mathrm{Mar}$. Available from: http://www.fhi.org/en.

10. European Monitoring Centre for Drugs and Drug Addiction. Protocol for the implementation of the EMCDDA key Indicator Drug Related Infectious Diseases (DRID). Draft Version 6 October 2006. Project CT.04. P1.337 [Internet]. Lisbon: EMCDDA; 2006 [cited 2009 Jun 2]. Available from: http://www.emcdda.europa.eu/themes/key-indicators/drid.

11. Weber B. A new automated fourth-generation HIV screening assay with sensitive antigen detection module and high specificity. Methods Mol Biol. 2005;304:245-55.

12. Lakshmi V, Ponamgi SP. Evaluation of an indigenous western blot kit for human immunodeficiency virus. Indian J Med Microbiol. 2002 OctDec;20(4):200-5.

13. Downie JC, Howard R, Bowcock B, Cunningham AL. HIV-1 antibody testing strategy: evaluation of ELISA screening and western blot profiles in a mixed low risk/high risk patient population. J Virol Methods. 1989 Dec;26(3):291-303. 
14. Friedman SR, Tempalski B, Cooper H, Perlis T, Keem M, Friedman R, et al. Estimating numbers of injecting drug users in metropolitan areas for structural analyses of community vulnerability and for assessing relative degrees of service provision for injecting drug users. J Urban Health. 2004 Sep;81(3):377-400.

15. Zhang D, Wang L, Lv F, Su W, Liu Y, Shen R, et al. Advantages and challenges of using census and multiplier methods to estimate the number of female sex workers in a Chinese city. AIDS Care. 2007 Jan;19(1):17-9.

16. European Monitoring Centre for Drugs and Drug Addiction. Annual report 2007. Lisbon: EMCDDA; 2007.

17. European Centre for Disease Prevention and Control. HIV/AIDS surveillance in Europe report 2007. Stockholm: ECDC; 2008.

18. Sanchez JL, Todd CS, Bautista CT, Botros BA, Khakimov MM, Giyasova GM, et al. High HIV prevalence and risk factors among injection drug users in Tashkent, Uzbekistan, 2003-2004. Drug Alcohol Depend. 2006 Apr;82 Suppl 1:15-22.

19. Abdala N, Krasnoselskikh TV, Durante AJ, Timofeeva MY, Verevochkin SV, Kozlov AP. Sexually transmitted infections, sexual risk behaviors and the risk of heterosexual spread of HIV among and beyond IDUs in St. Petersburg, Russia. Eur Addict Res. 2008;14(1):19-25.

20. Rácz J, Gyarmathy VA, Neaigus A, Ujhelyi E. Injecting equipment sharing and perception of HIV and hepatitis risk among injecting drug users in Budapest. AIDS Care. 2007 Jan;19(1):59-66.

21. Stark K, Sieroslawski J, Müller R, Wirth D, Godwod-Sikorska C, Bienzle U. Determinants of current HIV risk behaviour among injecting drug users in Warsaw, Poland. Eur J Epidemiol. 1996 Jun;12(3):315-7.

22. Stark K, Herrmann U, Ehrhardt S, Bienzle U. A syringe exchange programme in prison as prevention strategy against HIV infection and hepatitis B and C in Berlin, Germany. Epidemiol Infect. 2006 Aug;134(4):814-9.

23. Vidal-Trecan GM, Varescon-Pousson I, Boissonnas A. Injection risk behaviors at the first and at the most recent injections among drug users. Drug Alcohol Depend. 2002 Apr 1;66(2):107-9.

24. Valenciano M, Emmanuelli J, Lert F. Unsafe injecting practices among attendees of syringe exchange programmes in France. Addiction. 2001 Apr;96(4):597-606.

25. Gattari P, Spizzichino L, Valenzi C, Zaccarelli M, Rezza G. Behavioural patterns and HIV infection among drug using transvestites practising prostitution in Rome. AIDS Care. 1992;4(1):83-7.

26. Ehrenstein V, Horton NJ, Samet JH. Inconsistent condom use among HIV-infected patients with alcohol problems. Drug Alcohol Depend. 2004 Feb 7;73(2):159-66.

27. Maas B, Fairbairn N, Kerr T, Li K, Montaner JS, Wood E. Neighborhood and HIV infection among IDU: place of residence independently predicts HIV infection among a cohort of injection drug users. Health Place. 2007 Jun;13(2):432-9.

28. Forrester JE. Nutritional alterations in drug abusers with and without HIV. Am J Infect Dis. 2006;2(3):173-9.
29. Belak Kovačević S. Stress and facing among injecting drug users. Zagreb: Psychology Department, Faculty of Humanities and Social Sciences, University of Zagreb; 2004. (In Croatian.)

30. Choi SY, Cheung YW, Chen K. Gender and HIV risk behavior among intravenous drug users in Sichuan Province, China. Soc Sci Med. 2006 Apr;62(7):1672-84.

31. Bruneau J, Lamothe F, Soto J, Lachance N, Vincelette J, Vassal A, et al. Sex-specific determinants of HIV infection among injection drug users in Montreal. CMAJ. 2001 Mar 20;164(6):767-73.

32. Patrick DM, Tyndall MW, Cornelisse PG, Li K, Sherlock CH, Rekart ML, et al. Incidence of hepatitis $\mathrm{C}$ virus infection among injection drug users during an outbreak of HIV infection. CMAJ. 2001 Oct 2;165(7):88995.

33. WHO, UNODC, UNAIDS Technical guide for countries to set targets for universal access to HIV prevention, treatment and care for injecting drug users [Internet]. Geneva: WHO; 2009 [cited 2009 Jun 2]. Available from: http://www.who.int/hiv/pub/idu/targetsetting/en.

34. Muga R, Sanvisens A, Bolao F, Tor J, Santesmases J, Pujol R, et al. Significant reductions of HIV prevalence but not of hepatitis $\mathrm{C}$ virus infections in injection drug users from metropolitan Barcelona: 19872001. Drug Alcohol Depend. 2006 Apr;82 Suppl 1:S29-33.

35. Kerr T, Wood E, Small D, Palepu A, Tyndall MW. Potential use of safer injecting facilities among injection drug users in Vancouver's Downtown Eastside. CMAJ. 2003 Oct 14;169(8):759-63.

36. Wood E, Tyndall MW, Spittal PM, Li K, Kerr T, Hogg RS, et al. Unsafe injection practices in a cohort of injection drug users in Vancouver: could safer injecting rooms help? CMAJ. 2001 Aug 21;165(4):405-10.

37. Copenhaver MM, Johnson BT, Lee IC, Harman JJ, Carey MP; SHARP Research Team. Behavioral HIV risk reduction among people who inject drugs: meta-analytic evidence of efficacy. J Subst Abuse Treat. 2006 Sep;31(2):163-71.

38. Bealanger D, Godin G, Alary M, Bernard PM. Factors explaining the intention to use condoms among injecting drug users participating in a needle-exchange program. J Appl Soc Psychol. 2002 May;32(5):104763.

39. Su NY, Lee SH. Estimating the population size and colony boundary of subterranean termites by using the density functions of directionally averaged capture probability. J Econ Entomol. 2008 Apr;101(2):592-604.

40. Wiessing L, van de Laar MJ, Donoghoe MC, Guarita B, Klempová D, Griffiths P. HIV among injecting drug users in Europe: increasing trends in the East. Euro Surveill. 2008 Dec 11;13(50):pii 19067.

41. You N, Xuan Mao C. Population size estimation in a two-list surveillance system with a discrete covariate. Biometrics. 2008 Jun;64(2):371-6.

Received July 2, 2009

Accepted in revised form November 11, 2009 